\title{
Understanding the Neuromechanisms of Consumer Behavior in Advertising Industry ${ }^{1}$
}

\author{
Norsiah Fauzan \\ Department of Cognitive Science, Faculty of cognitive Science and Human Development, \\ Universiti Malaysia Sarawak, 94300 Malalysia. \\ nursiahfauzan@gmail.com
}

Tel: +60 82 581515, Fax: +60 82581567 ,

\begin{abstract}
The objective is to acknowledge the relevance of the unconsciousness in the consumers' behavior by providing a new point of view based on the innovative findings of cognitive neuroscience. This paper highlights recent studies on emotion, and memory, focusing on their implication in the advertising process. The intention of this paper is to open our eyes to new scientific findings that may well mean a new way of understanding how advertising works, giving a new value to the role of emotion and consciousness. The 21st century gives us the opportunity to look once more at the perspective of incorporating validated scientific contributions based on the new discoveries about brain functioning. This article will build bridges between these scientific results and current advertising practice in a way that allows us to introduce a new point of view which redefines the influence of emotions and its role in the processes of memory, attention, reasoning and decision-making.
\end{abstract}

Keywords: Consumer neuroscience, emotions, advertising

\section{INTRODUCTION}

This article proposes the methods of neuroscience to understand the consumers' choice and decision making in response to advertisement which further allow the appropriate design of graphics or strategy for neuro marketing. The primary objective is to highlight to a broad audience the prospect of turning to neuroscience biological variables to inform models of marketing and consumer decision making. The research in consumers' decision making has benefitted from the revealed preferences perspective that follows the tradition of focusing on observation on what people actually choose or using questionnaire and interview to get their reasoning for their choice. However, it actually ignores the mechanisms inside "the black box" in which the decisions are made in relation to other additional variables such as stress, intentions, attitudes and memory which facilitates insights in providing context and testable constraints. These biological variables in neuroscience and its interactions with sociological variables adds value to decision making and consumer choice research. Understanding of underlying mechanism that led to the observed choice is crucial so that one is in a better position to understand the consumer loyalty to a brand, understanding of contextual influences which interact with the different neural circuitry that leads to a different choice, and most importantly the influences on choice made by consumer. Such knowledge can be important in many domains such as marketing and advertising industry, legal decisions and medical. Neuroimaging tools in neuroscience yield valuable information for the interpretation

of choice data. Neuroscience helps us to explore the hidden elements of the decision process. The decision neuroscientist might draws on the concept and techniques from neuroscience to inform research in advertisement and marketing.

\section{Objectives}

\footnotetext{
1 This paper has been published at: Journal of Applied Sciences Research, Received: 27 March, 2015; Revised: May 13, 2013; Accepted: May 22, 2013, , JOURNAL home page: http://www.aensiweb.com/jasr.html
} 
The objective of this research is to propose the methods of neuroscience to understand the consumers' choice and decision making in response to advertisement which further allow the appropriate design of graphics or strategy for neuro marketing. Understanding the relevance of the unconsciousness in consumers' behavior by providing a new point of view from the innovative findings of cognitive neuroscience will open our eyes to new scientific findings that may well mean a new way of understanding how advertising works, giving a new value to the role of emotion and consciousness.

\section{Methods}

To understand the mental process involved in consumer behavior and advertising, the researcher will first explain associated areas of the brain such as the limbic system where the Amygdala, hypothalamus and hippocampus are located and implicated in the study of consumer behavior in advertisement. This will be followed by the role of emotions and memory in advertisement to provide a more understanding on the consumer behavior and their responses to the advertisement with reference to the synthesis on related research. Finally, suggestions are given on how and appropriate devices to be used for the research.

\section{NeuroMechanism in Advertisement}

Figure 1 : Limbic System

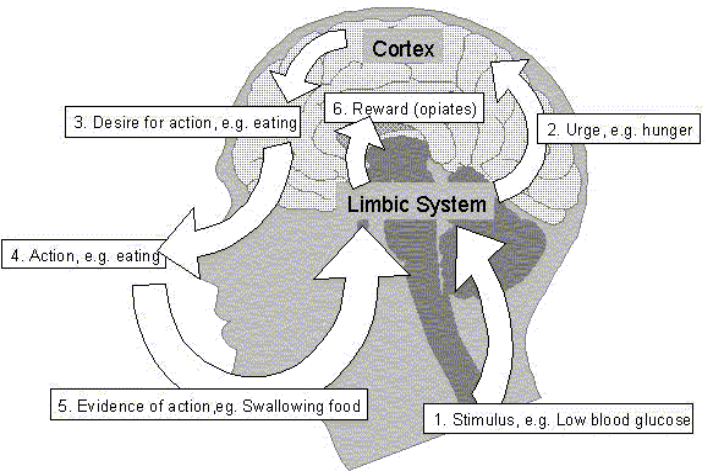

Human behavior is a manifestation of both cognitive and affective processing. Figure. 1 above demonstrated the limbic system, Thalamus in the limbic system converts the desire and needs as an urge or motivation to an urge within the cortex. The cortex translates the urge into a desire for something specific. It is from the limbic system that explains the motivational aspect of desire that provides the urges. Very often, the urges have priority and forces other matters aside. The underlying urge becomes the desire or needs from a person's mental state which later translated into actions and steps to satisfy the internal nagging or desire and needs for something specific. The study of emotions has been crucial in advertisement research due to significant role of memory in advertisement. Amygdala within the limbic system motivates the consumer behavior to purchase, hippocampus keeps the memory and experiences of the consumer regarding the products or brand and hypothalamus, a center for the limbic system which is highly connected with the frontal parts of the brain which is responsible for judgement and decisions.

\section{0 Role of Emotion in Advertisement}

Emotion is a process that varies in intensity and exhibits variety of concomitant indices such as physiological changes in heart rate, blood pressure and adrenalin levels. It resides in individuals and is intense enough to elicit "feelings experiences". It produce arousal and attention to the "emotional message" or stimulus as pictured in the advertisement. The commercial message is a vehicle that arouse flow of feelings that most people report as emotional experiences. The advertisers can go beyond the traditional focus groups to tap into consumers' subconscious minds by relying on biometric 
indicators by using EEG for brainwave activity, heart rate and respiratory to effectively target consumers. This methodology and reliance on scientific evidence goes against the creative 'gut' instinct which led advertising decisions for decades. The advertiser can make a claim about being 'delicious' to convince the consumers on the chocolate brand advertised but is there any scientific evidence that can make people believe the advertisement. The neuroscience approach would help the advertising industry to persuade with scientifically verified results by measuring the actual pleasure of eating the chocolates. The fastest way is to actually bring a portable EEG device to measure the brainwave activity while eating the chocolate brand they advertised. The pleasure experience can be measured using an EEG and analyzing alpha waves $(8-13 \mathrm{~Hz})$, beta waves $(13-30 \mathrm{~Hz})$ and theta waves $(4-7 \mathrm{~Hz})$. The expected brainwave activity will be alpha waves $(8-13 \mathrm{HZ})$ and the specific brain regions activated will be the nucleus accumbens, part of the limbic system responsible for emotions, pleasure and reinforcement. Take for example an emerging chocolate brand "BeyondDark" in UK that substantiates their claim of "ultimate chocolate feel good treat" marketing campaign using scientific evidence from EEG brainwaves to measure pleasurable feeling, just one chocolate drop elicited a pleasurablel feeling of 65 . The company collaborates with Birkbeck University and MyndPlay company to provide the EEG headsets and analysed the brainwave data for the study on Measure of Pleasure to create a pleasurable scale to compare how eating chocolate ranked against other common 'pleasurable' activities like finding money, blowing bubbles, and stroking a puppy. The results showed that finding money elicited strongest reaction followed by eating a piece of BeyondDark chocolates and playing with kittens.

\section{0 Consumer memory}

Advertisers might want to implicate on the consumer memory by using comedy, drama and suspense. Happiness, anger and sadness while watching the ads must have left stronger emotional trace on the episodic memory of specific events experienced by an individual. When people watch commercial ads, people tends to process the audio and video events in the ads in addition to their internal physiological states such as thought and feelings. The episodic traces vary in strength depending on the intensity of the person's experience, and the meaningfulness of the information and their understanding. When people are emotionally aroused when watching commercials, it will leave stronger episodic memory than those experience without arousal [5].

Having that feeling embedded in memory, and creating the emotional connection that makes the customer want to return and in fact creating sense of loyalty. The economics behind experience are all around loyalty, recommendation, customer lifetime value. Over time, emotions and their corresponding bodily change (s) become associated with particular situations and their past outcomes. In decision making, most people consciously or subconsciously associate these physiological signals, and their evoked emotions with their past outcomes, and they bias decision-making toward certain behaviors. Evidence from brain scans shows that emotions impinge directly on consumer decision making. That fits with what the psychology of customer experience is about: finding that emotional connection. Other evidence from neuroscience highlights the importance of subconscious and memorable moments. The subconscious processes 200,000 times more information than the conscious mind and processes emotions about 10 times faster than the conscious mind. This indicates the degree of correlations between ad memorization and the degree of affective content within the advertisement. These affective advertising activates the amygdala, and orbitofrontal cortices.

\section{0 Brief Branding moments}

In terms of establishing advertising effects, research has shown that there are certain periods of commercials that are far more significant for the consumer. These are referred to as "branding moments" and are thought to be the most engaging parts of the commercial. It was suggested that the strength of a commercial with regard to its effect on the consumer can be evaluated by the strength of its unique branding moments. Usually, the branding moment are short segments with scene duration lasting longer than 1.5 seconds which have been shown to be more memorable. In 2004, McClure et al conducted a study to investigate the difference in branding between Coca cola and Pepsi. Participants had to indicate which cola they prefer while their brain was scanned. Results showed that when subjects tasted samples of Pepsi and Coke with and without the brand's label, they reported different preferences [4]. Without labels, subjects evaluate both drinks similarly. When drinks were labeled, subjects report a stronger preference for Coke. Coke managed to trigger certain associations in our brain, and simply seeing their logo is enough to make a drink taste better. 
Both drinks produced equal activation in the ventromedial prefrontal cortex (VMPC), which is thought to be activated because the taste is rewarding. When the subjects were informed of the brand names the consumers preferred Coke, and only Coke activated the ventromedial prefrontal cortex, suggesting that drinking the Coke brand is rewarding beyond simply the taste itself. There was also significant activation in the hippocampus and dorsolateral prefrontal cortex when subjects knew they were drinking Coke. These brain structures are known to play a role in memory and recall which indicates the subjects to associate their present drinking experience to previous brand associations. The results of this study suggested that the Coke brand has much more firmly established itself as a rewarding experience. However, in another study by Koenigs \& Tranel [3], there are people who are less sensitive to this branding effect: subjects with ventromedial prefrontal cortex damage (an area involved in emotional processing. Unlike their normal counterpart, these patients maintained their preference for Pepsi. The authors conclude that lacking the normal affective processing, VMPC patients may base their brand preference primarily on their taste preference. " The VMPC thus act as a gate that let emotional memories affect present evaluations.

Neuroscience adds value to consumer studies and on the other hand consumer research provides real world applications for neuroscience study. When tracking brain functions, neuroscientists generally use either electroencephalography (EEG) or functional magnetic resonance imaging (fMRI

technology. EEG measures fluctuations in the electrical activity directly below the scalp, which occurs as a result of neural activity. By attaching electrodes to subjects' heads and evaluating the electrical patterns of their brain waves, researchers can track the physiological changes and or intensity of responses such as anger, lust, disgust, and excitement. In 2008, junk food giant Frito lay hired a neuromarketing to look into consumers respond to Cheetos, the top-selling brand of cheese puffs in USA. The consumer researchers used EEG technology on a group of participants, the participants respond strongly to the fact that eating Cheetos turns their fingers orange with residual chees dust. Karmarker cited an articles in August 2011 [2] that the EEG patterns indicated a sense of giddy subversion that consumers enjoy over the messiness of the product. With the data in hand, the company moved ahead with an ad campaign featuring a series of 30 second TV commercial in which the Cheetos mascot, Chester Cheetah, encourages consumers to commit subversive acts with Cheetos. (In one commercial, an airline passenger quietly sticks Cheetos up the nostrils of a snoring seatmate. Problem solved. ) The campaign garnered Frito-Lay a 2009 Grand Ogilvy Award from the Advertising Research Foundation.

Research using neuroscience has given two added advantage. Firstly, the ability to show what's going on inside the brain and secondly, the transparency, because showing the results of scientific paper is more believable than giving what perceived to be the correct answers from a survey. The advances in sciences will make baseless advertising claims lose its value and brilliant products and truthful claims increasingly triumph. The two commonly used devices are EEG and fMRI. EEG is portable and can easily record the brain activity with the cap of electrodes sitting on the surface of your head, however the recording did not get to the deep areas of the brain. On the other hand, the fMRI uses a giant magnet, often 3 Teslas strong, to track the blood flow throughout the brain as test subjects respond to visual, audio, or even taste cues. fMRI gives researchers a view into the aforementioned pleasure center. "The more desirable something is, the more significant the changes in blood flow in that part of the brain, "But this sophisticated piece of equipment are costly and has few technological limitations. , fMRI requires them to lie very still inside a machine that can be intimidating. EEG allows subjects to move around during testing.

\section{Conclusion}

Most of the neuroscience studies involved brain scanning conducted in medical or technological environment. More research need to be done in supermarkets or shopping mall for consumer decision making. Testing underlying neurophysiological states is difficult because it is unclear exactly how various factors are perceived in the human mind. Consumers reaction and decision making process is not simply a biological variables but interaction between biological and sociological variables and culture. It was proposed that neuroscience adds value to consumer neuroscience research by enhancing ability to make iinference beyond the usual variables and paradigms. There are concerns over the value and the potential usage of consumer neuroscience data. The potential for enhanced consumer welfare is certainly present but equally present is the potential for the information to be used inappropriately for individual gain. Currently, Consumer neuroscience research is a compilation of only loosely related subjects that at this point, is unable to produce any collective conclusions. 


\section{References}

[1] Ambler T, Burne T. The impact of affect on the memory of advertising. Journal of Advertising Research. 1999;39 (2):25-34

[2] Carmen Nobel (2012), What Neuroscience tell us about Consumer desire. WORKING KNOWLEDGE, the thinking that leads. Harvard Business school. Retrieved fromhttp://hbswk. hbs. edu/item/6950. html

[3] Koenigs, M. , Tranel, D. (2007). Prefrontal cortex damage abolishes brand-cued changes in cola preference. Social Cognitive and Affective Neuroscience, 3 (1), 1-6. DOI: 10. 1093/scan/nsm032

[4] McClure, S. M. , Li, J. , Tomlin, D. , Cypert, K. S. , Montague, L. M. , \& Montague, P. R. (2004). Neural Correlates of Behavioral Preference for Culturally Familiar Drinks. Neuron, 44 (2), 379-387.

[5] Pillemer, Davit B. (1984), "Flashbulb Memories of the Assassination Attempt on President Reagan"' Cognition 16, 63-80.

[6] Plassmann, H. , O'Doherty, J. , Shiv, B. , Rangel, A. (2008). Marketing actions can modulate neural representations of experienced pleasantness. Proceedings of the National Academy of Sciences, 105 (3), 1050-1054. DOI: 10. 1073/pnas. 0706929105 